\title{
Analysis of the Impact of Decreasing the Width of Direct Stairs in Apartments on RSET for All Occupants in Korea
}

\author{
Sang Im Lee ${ }^{1}$, Ha-Sung Kong*2 \\ ${ }_{1 * 2}$ Fire and Disaster Prevention, Woosuk University Graduate Sch., WANJU, Korea \\ idol10041004@nate.com¹, 119wsu@naver.com²
}

Article History: Received: 11 January 2021; Accepted: 27 February 2021; Published online: 5 April 2021

\begin{abstract}
This study analyzed the RSETs for 11-story or less apartments where the building-related laws were not retroactively applied, with consideration of the decrease of direct stairs width due to obstacles piled up on the direct stairs. The RSET was shown to be 631.8 seconds when the width of the direct stairs was $1,260 \mathrm{~mm}$. The evacuation time exceeded 5 minutes even when there were no obstacles due to the delayed evacuation start time. The risk increased when the width of the direct stairs was decreased to $960 \mathrm{~mm}, 760 \mathrm{~mm}$, and $560 \mathrm{~mm}$ because of obstacles, and the RSETs were 768.8 seconds, 803.3 seconds, and 834.4 seconds respectively. There are various ways to eliminate the occurrence of obstacles on direct stairs which increase RSET : First, it is necessary to remove the exception that permits the placement of obstacles on the stairs. Second, penalties for the placement of obstacles on the direct stairs should be enforced as written. Third, the fire safety managers need the authority to act on behalf of the fire officials. Lastly, it is necessary to encourage residents to report instances of obstacle accumulation. Henceforth, more research is needed on the spread speed of smoke and toxic gases depending on whether fire doors are installed through fire simulation.
\end{abstract}

Keywords : Pathfinder, Apartment, Direct Stairs Width, Required Safe Egress Time, Obstacles.

\section{Introduction}

Apartments with eleven stories or less that were approved for business before December 30, 2003 do not have fire doors installed on all floors. As the building-related laws [1] are not retroactively applied, apartments subject to the law at the time of construction are not equipped with fire doors, so the possibility of initial extinguishment in the event of a fire in the housing unit is low, and there is a high risk of human casualties in evacuation due to the rapid inflow of toxic gases and smoke through the direct stairs. In particular, residents are insensitive towards safety due to the frequent occurrence of false alarms in old apartments, and even if the fire alarm sounds in the event of a fire, residents consider it a false alarm and do not evacuate, which could lead to a delay in the evacuation starting time. Increased RSET due to delayed evacuation time may increase the risk of human casualties. It was also reported that the XX Fire Department conducted a special fire investigation into apartment houses and found that the safety facilities and evacuation routes were "poor"[2].

In some cases, there are many obstacles on the stairs in the event of a fire in an apartment building built before the 1990s, resulting in longer escape times. Therefore, it is necessary to study the direct stairs width of apartments that do not have fire doors installed because it may be difficult to secure escape routes due to the accumulation of obstacles such as bicycles, strollers, waste boxes, and recyclable materials.

Existing studies on stair width include Choi Joon-ho et al (2014) [3,18], Lee Jung-soo, Moon Jung-ho (2010), Lee Jung-soo, Kwon Hong-soon (2012)[5]. Most of the studies are about evacuation safety in the event of a fire based on the width of corridors and stairs in goshiwon, high-rise apartments, and university education facilities. Apartments with eleven stories or less that are not retroactively subject to the building-related laws are not equipped with fire doors. Under these circumstances, no research has yet been conducted with a Pathfinder evacuation simulation, in which the width of the direct stairs is reduced by placing obstacles on the direct stairs.

Therefore, this study attempts to analyze the RSET by assuming that the width of the direct stairs decreases due to the accumulation of obstacles, such as bicycles, strollers, waste boxes, and recyclable materials, which are placed on the direct stairs of apartments with eleven or less stories in which fire doors are not installed, all of which has not been previously studied together.

\section{Pathfinder Evacuation Simulation}

2.1 Evacuation Scenario

2.1.1. Simulation Target Overview

XX apartment located in XX-gu, Korea, was approved for business on December 30, 2003 and consists of 10 buildings with a total of 625 housing units. Five of the buildings are apartment complexes with 15 floors or more, with up to 19 floors above ground and 2 floors underground, and the other five buildings are apartment 
complexes with 11 floors or less, with up to 15 floors above ground and 2 floors underground. The five apartment complex buildings in XX-dong with 11 floors or less were designated as the target for this study. In the event of a fire in a housing unit, it is difficult to extinguish the fire in the initial stage because sprinkler facilities are not installed in the apartments. Each floor has four housing units, is directly connected to the direct stairs, and has one entrance and one direct stairs. The floor plan and floor area of each housing unit of the apartments are as shown in Figure 1.

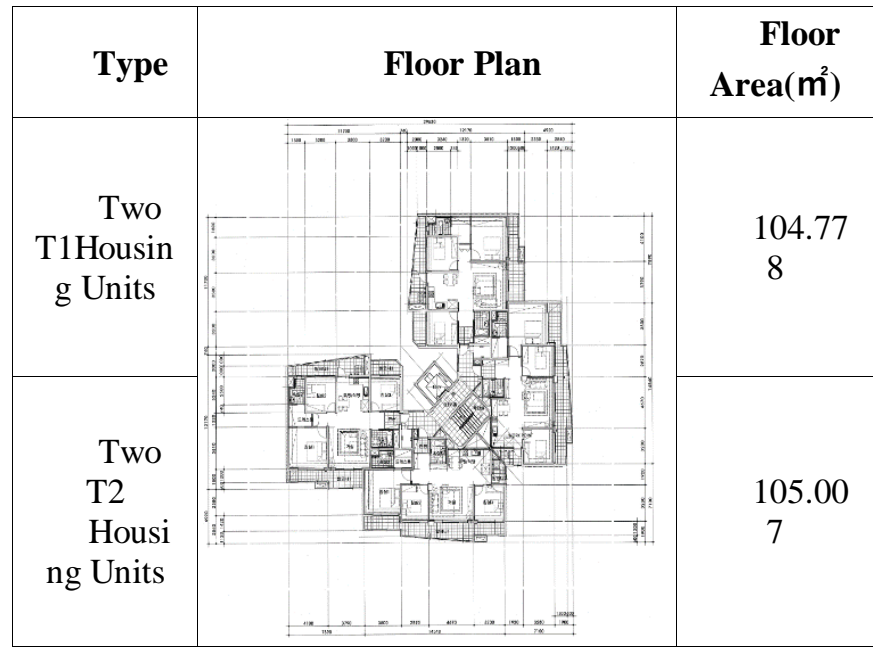

Figure 1. Floor Plan and Floor Area of Target Site

1.1.2. Structure and Input Variables of Direct Stairs

To maximize the refuge barrier caused by the reduction of the direct stairs width, conduct a simulation of evacuation downwards from the 11th floor, which is the top floor, to the first floor. The occupants were calculated as the capacity of each area, and the space used in the Pathfinder evacuation simulation is a U-shaped stairway with a landing as shown in Figure 2, with a stair width of $1,260 \mathrm{~mm}$, a rise of $170 \mathrm{~mm}$, a run of $270 \mathrm{~mm}$, and a total rise of $2,700 \mathrm{~mm}$.

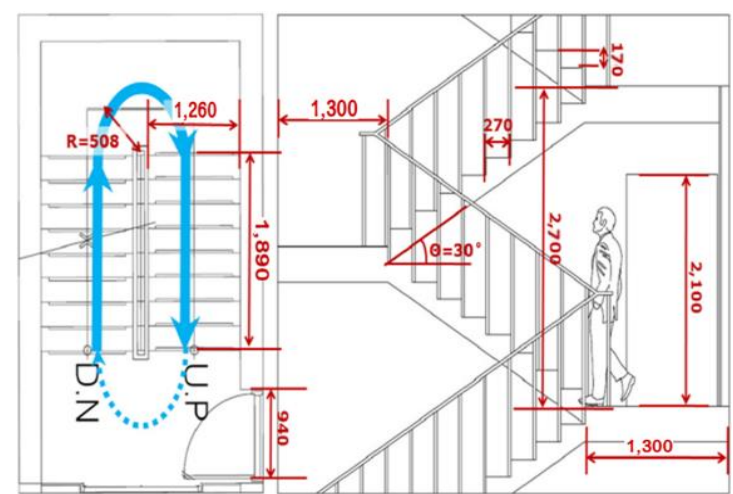

Figure 2. Floor Plan and Cross Section Dimensions of Target Apartment Direct Stairs.

One elevator is installed, but it cannot be used for evacuation in the event of a fire, so occupants cannot use it to evacuate. The stair width in the Pathfinder evacuation simulation program is set at $1,260 \mathrm{~mm}$, which is the width of the actual target apartment direct stairs, and depending on the type of obstacle, the width of the direct stairs is reduced by $300 \mathrm{~mm}, 500 \mathrm{~mm}$, and $700 \mathrm{~mm}$ to create scenarios as shown in Table 1.[6][7]The Environmental Obstacles

Table 1. Input Variables of Direct Stairs

\begin{tabular}{|c|c|c|r|r|r|}
\hline \multirow{2}{*}{$\begin{array}{c}\text { Scenari } \\
\mathbf{o}\end{array}$} & $\begin{array}{c}\text { Condition of } \\
\text { Direct } \\
\text { StairsWidth }\end{array}$ & $\begin{array}{c}\text { Stair } \\
\text { Width } \\
(\mathbf{m m})\end{array}$ & $\begin{array}{c}\text { Rise } \\
(\mathbf{m m})\end{array}$ & $\begin{array}{c}\text { Run } \\
(\mathbf{m m})\end{array}$ & $\begin{array}{c}\text { Total } \\
\text { Rise } \\
(\mathbf{m m})\end{array}$ \\
\hline 1 & $\begin{array}{c}\text { Direct stairs } \\
\text { with no obstacles }\end{array}$ & 1,260 & & & 270 \\
\cline { 1 - 2 } 2 & $\begin{array}{c}\text { Direct stairs } \\
\text { with a 300mm }\end{array}$ & 960 & & 2700 \\
\hline
\end{tabular}




\begin{tabular}{|c|c|c|c|c|}
\hline & $\begin{array}{c}\text { width reduction } \\
\text { due to bicycle } \\
\text { placement }\end{array}$ & & \multirow{2}{*}{. } \\
\hline 3 & $\begin{array}{c}\text { Direct stairs } \\
\text { with a 500mm } \\
\text { width reduction } \\
\text { due to stroller } \\
\text { placement }\end{array}$ & 760 & & \\
\hline 4 & $\begin{array}{c}\text { Direct stairs } \\
\text { with a 700mm } \\
\text { width reduction } \\
\text { due to waste box } \\
\text { and recyclable } \\
\text { material } \\
\text { placement }\end{array}$ & 560 & & \\
\hline
\end{tabular}

2.1.3. Calculation and Placement of the Occupants

In order to calculate the number of people to be accommodated in the 44 housing units across the 11 floors, the number of people to be accommodated for apartments in residential use was calculated to be six people per housing unit $\left(105.007 \mathrm{~m}^{2} \div 18.6 \mathrm{~m}^{2}[8]=5.64\right)$. Also, as in Figure 3, the occupants were considered to be evenly distributed in each housing unit.

Table 2. Occupant Calculation

\begin{tabular}{|c|c|c|c|c|}
\hline $\begin{array}{c}\text { Occupa } \\
\text { ncy }\end{array}$ & $\begin{array}{c}\text { Are } \\
\text { a per } \\
\text { person } \\
\left(\mathrm{m}^{2}\right)\end{array}$ & $\begin{array}{c}\text { Occupa } \\
\text { nts per } \\
\text { housing } \\
\text { unit }\end{array}$ & $\begin{array}{c}\text { Occupa } \\
\text { nts per } \\
\text { floor }\end{array}$ & $\begin{array}{c}\text { Total } \\
\text { Occupants }\end{array}$ \\
\hline $\begin{array}{c}\text { Apartme } \\
\text { nt }\end{array}$ & 18.6 & 6 & 24 & 264 \\
\hline
\end{tabular}

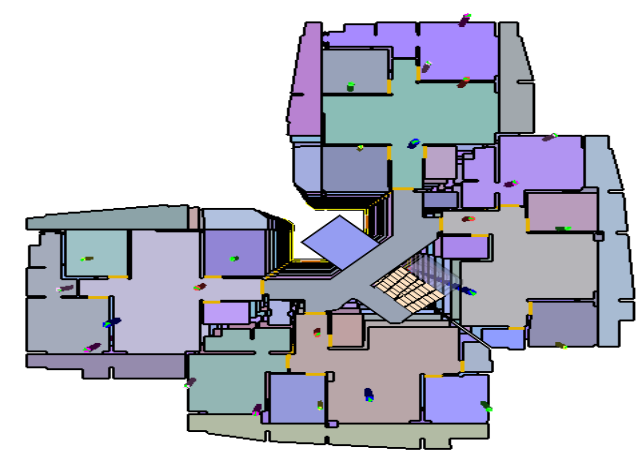

(a)

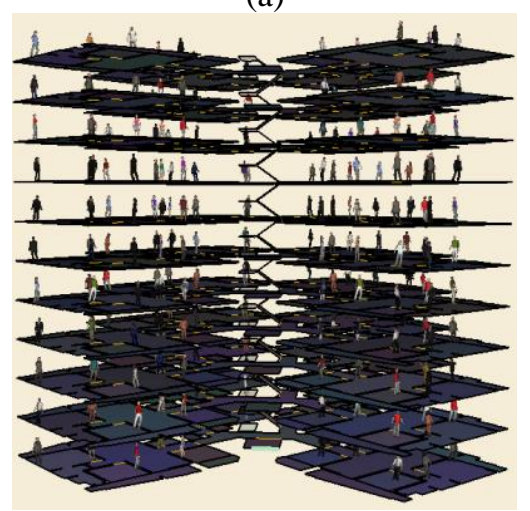

(b) 
Analysis of the Impact of Decreasing the Width of Direct Stairs in Apartments on RSET for All Occupants in Korea

Fig 3. Placement of Occupants

(a) Floor Plan, (b) Elevation Drawing

\subsubsection{Input Variables of Occupants}

The input variables of the apartment occupants for the Pathfinder evacuation simulation are organized per housing unit and include the age and gender composition, walking speed, and reaction time. Based on the calculation that there are 6 people per $105.007 \mathrm{~m}^{2}$ housing unit, the composition consisted of two elderly citizens in their 70s, two adults in their 30s, and also two children under the age of 10 in order to include younger people as well. The Pathfinder evacuation simulation program was used by separating men [9] and women [10] based on body dimensions of shoulder width and height, and the walking speed by age and gender was made into an input variable, as shown in Table 3.

Table 3. Input Variables of Occupants

\begin{tabular}{|c|c|c|c|c|}
\hline $\begin{array}{c}\text { Occupant } \\
\text { Composition Per } \\
\text { Housing Unit }\end{array}$ & Age & $\begin{array}{c}\text { Shoulder } \\
\text { Width (cm) }\end{array}$ & $\begin{array}{c}\text { Height( } \\
\mathbf{c m})\end{array}$ & $\begin{array}{c}\text { Applied Walking } \\
\text { Speed (m/s) }\end{array}$ \\
\hline A girl & 7 & 29.4 & 120.1 & \multirow{2}{*}{$0.77[11]$} \\
\hline Aboy & 10 & 33.2 & 138.6 & \multirow{2}{*}{$1.19[12]$} \\
\hline Awoman & $30-34$ & 37.1 & 160.2 & \multirow{2}{*}{$0.92[13]$} \\
\hline A man & $30-34$ & 43.1 & 173.7 & 149.1 \\
\hline An elderly woman & Over 70 & 36.5 & 162.4 & \\
\hline
\end{tabular}

\subsection{Evaluation Basis}

Due to frequent false alarms, residents mistake actual fire alarms for false alarms and do not evacuate even if a fire breaks out. Therefore the security guard needed to knock on the occupants' doors to notify the 264 occupants to evacuate, then the time it took the guard to come down to the first floor was recorded, which was approximately five minutes, and the evacuation start time was set to 300 seconds after the fire. In a 11-story or less apartment complex, residents are familiar with the building's interior, alarm and evacuation routes, but the evacuation time was set at less than five minutes, assuming that they were likely to be asleep in the event of a fire at night, and that they were notified of the fire through non-training staff who were night guards.[14] However, in this study, the evacuation start time is already 5 minutes, so the focus is on the increase or decrease of RSET for each scenario because the evacuation time has already been exceeded.

\section{Rsesults and Consideration}

As a result of analyzing RSET by reducing the direct stairs width for each scenario, the RSET derived through the Pathfinder evacuation simulation is as shown in Figure 4. RSETs according to simulation variables with reduced direct stairs widths were 632 seconds for Scenario 1 with direct stairs width of 1,260mm, 769 seconds for Scenario 2 with direct stairs width of $300 \mathrm{~mm}, 803.5$ seconds for Scenario 3 with direct stair width of $500 \mathrm{~mm}$, and 834.5 seconds for Scenario 4 with direct stairs width of $700 \mathrm{~mm} .^{1}$

${ }^{1}$ Due to the nature of the Pathfinder program, there is a difference of 0.1-0.2 seconds between the summary data and picture data. The summary data was used in this study. 
Sang Im Lee ${ }^{1}$, Ha-Sung Kong*2

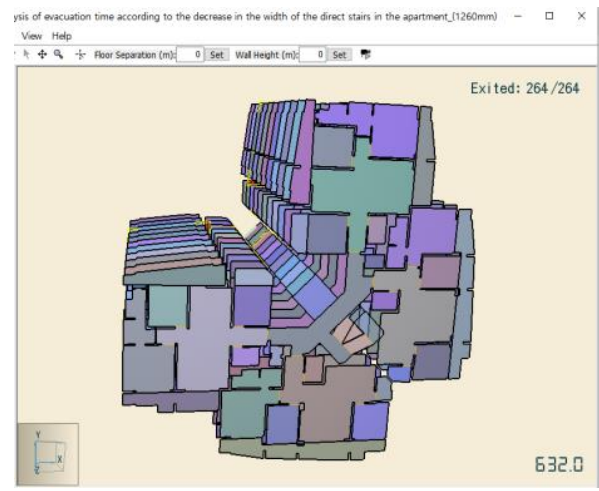

(a)

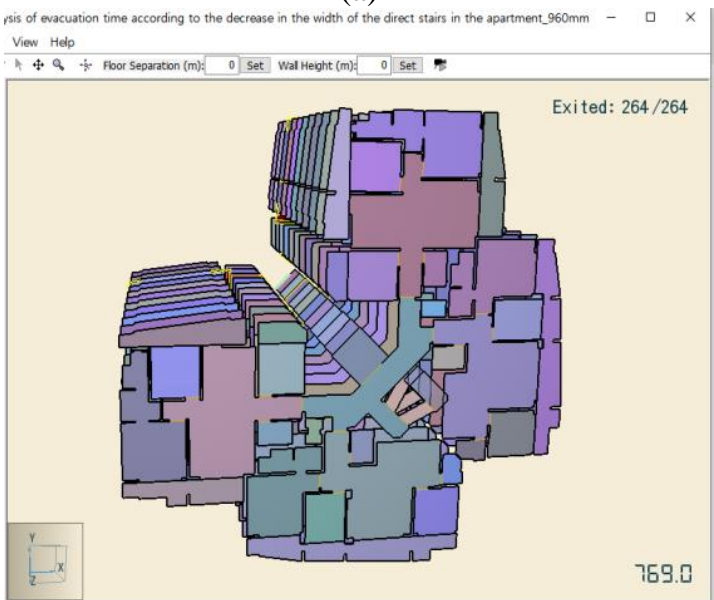

(b)

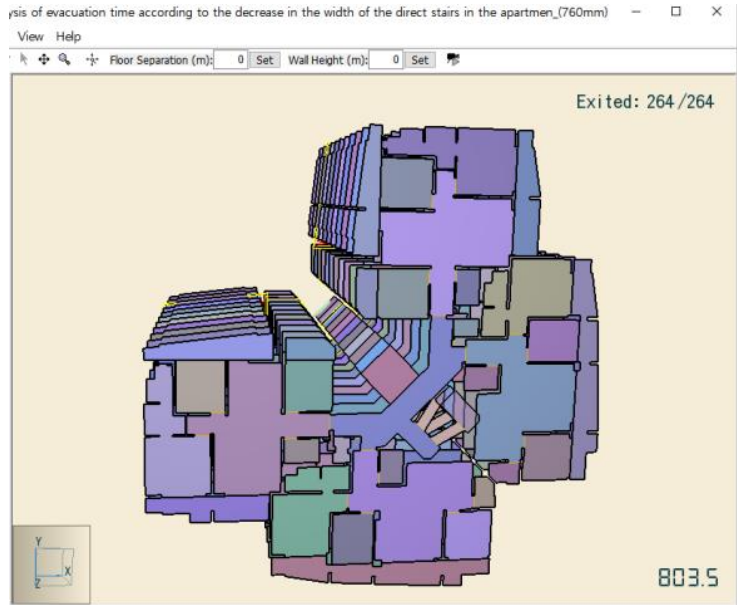

(c) 


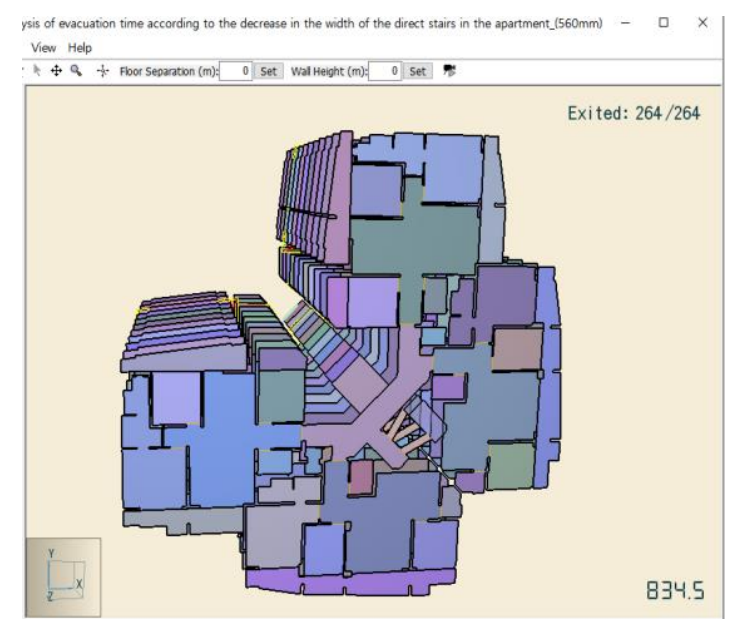

(d)

Fig 4. Evacuation Time according to Decrease of Direct Stairs Width

(a) Direct Stairs Width of 1,260mm, (b) Direct Stairs Width of $960 \mathrm{~mm}$, (c) Direct Stairs Width of $760 \mathrm{~mm}$,

(d) Direct Stairs Width of $560 \mathrm{~mm}$

As shown in Table 4, RSETs were different when the width of the direct stairs was reduced. The RSET was increased by $21.68 \%$ for $960 \mathrm{~mm}, 27.28 \%$ for $760 \mathrm{~mm}$, and $32.07 \%$ for $560 \mathrm{~mm}$ respectively. Therefore, the risk will increase as the RSET increases because of a decrease in the width of the direct stairs due to the obstacles, where the direct stairs are the only evacuation route to the only exit on the first floor of apartments with eleven stories or less.

Table 4. RSET for All Occupants

\begin{tabular}{|c|c|c|}
\hline $\begin{array}{c}\text { Direct Stairs Width } \\
(\mathbf{m m})\end{array}$ & RSET(s) & Variation (\%) \\
\hline 1,260 & 631.8 & 100 \\
\hline 960 & 768.8 & $137.0(+21.68)$ \\
\hline 760 & 803.3 & $171.7(+27.18)$ \\
\hline 560 & 834.4 & $202.6(+32.07)$ \\
\hline
\end{tabular}

To eliminate the occurrence of obstacles on the direct stairs which contribute to the increase in RSET, the following suggestions are made:

First, it is necessary to remove the exception that permits the placement of obstacles on the stairs. It is prohibited[15] to stack or place obstacles around evacuation facilities, fire areas, and fire prevention facilities. However, in the case of apartment complexes, the following instances of storage or placement are not subject to a fine for negligence [16]:

1) If a bicycle is placed in an orderly fashion in a corridor or passageway,

2) If the simple daily necessities that can be moved immediately as a temporary storage item are stored without interfering with evacuation and firefighting, etc.,

3 ) If the end of the corridor is blocked by items but they do not interfere with evacuation and firefighting, etc.

Improvements are needed to remove the exception concerning the accumulation of obstacles so that they do not interfere with evacuation.

Second penalties for the placement of obstacles on the direct stairs should be enforced as written. In the case of an obstacle, 500,000 won to 2 million won in fines are to be imposed, but there is an exception in apartments which permits the placement of daily items if they can be moved immediately, and fines are replaced by local corrective measures and education by fire officials, which results in a vicious cycle of repeatedly placing obstacles as no fines are imposed.[17] It is necessary to enforce the penalty concerning the accumulation of obstacles in accordance with the regulations without exceptions, in order to eliminate the occurrence of obstacles.

Third, the fire safety managers need the authority to act on behalf of the fire officials. The reality is that the fire safety managers appointed to the apartment are only responsible for the management and do not have the authority to order the removal of obstacles. It is necessary to grant fire safety managers the authority which fire 
officials have to conduct and report through the revision of the law on obstacles placed on corridors or stairs, making it easier for the direct stairs to secure escape routes.

Lastly, it is necessary to encourage residents to report instances of obstacle accumulation. Residents tend to assume it is fine to place obstacles on the direct stairs, and even those who know it is wrong do not seem to have the will to report them to related agencies for reasons such as conflicts with neighbors [18]. In the event that obstacles are placed in the direct stairs according to the detailed standards for reporting illegal activities such as blocking emergency exits, it is necessary to encourage occupants to make a report by rewarding the reporter.

\section{Conclusion}

The study analyzed the required evacuation time for apartments with eleven or less stories where the buildingrelated laws are not retroactively applied, taking into account 300 seconds of evacuation start time, and when the direct stairs width decreases due to obstacles placed on the direct stairs, as well as when the occupants do not attempt to evacuate due to the expectation of false alarms.

(1) When the width of the direct stairs is $1,260 \mathrm{~mm}$, the RSET was shown to be 631.8 seconds. Since the evacuation time was 300 seconds, the evacuation time exceeded 5 minutes even if there were no obstacles.

(2) When the width of the direct stairs is $960 \mathrm{~mm}$, the RSET is 768.8 seconds, an increase of 137 seconds from $1,260 \mathrm{~mm}$.

(3) When the width of the direct stairs is $760 \mathrm{~mm}$, the RSET is 803.5 seconds, an increase of 171.7 seconds from $1,260 \mathrm{~mm}$.

(4) When the width of the direct stairs is $560 \mathrm{~mm}$, the RSET is 834.4 seconds, an increase of 202.6 seconds from $1,260 \mathrm{~mm}$.

As such, decreasing the width of the direct stairs resulted in an increase in the RSET, which increased the risk.

In order to eliminate the occurrence of obstacles on the direct stairs which increase RSET, it is necessary to first remove the exception that permits the placement of obstacles on the stairs. Second, penalties for the placement of obstacles on the direct stairs should be enforced as written. Third, the fire safety managers need the authority to act on behalf of the fire officials. Lastly, it is necessary to encourage residents to report instances of obstacle accumulation. More research is needed on the spread speed of smoke and toxic gases depending on whether fire doors are installed through fire simulation.

\section{References}

1. Korea Ministry of Government Legislation, 「Rules on the Standards for Evacuation, Fire Protection, etc. of Buildings」Article 14 Paragraph 2,Revision 06-Aug 2019.

2. KBSnewsMay $11,2020$.

3. https://news.naver.com/main/read.nhn?mode=LPOD\&mid=tvh\&oid=056\&aid=0010833397

4. Jun-Ho Choi, Gyu-Yeob Jeon, Won-hwa Hong, Study on How Width of Evacuation Stair Influences Evacuation Time and Evacuaee's Vertical Distribution at a High-rise Apartment Housing, The Architectural Institute of Korea collection of academic presentations, Vol.27, No.1, p.740, 2007.

5. Jeong-Soo Lee, Jae-Ho Mun, A Study on the Evacuation Time According to the Width of Corridor, Stair and Density of Evacuee in University Education Facilities, Korean Institute of Educational Facilities, Vol.17, No.1, p.17, p.20, 2010.

6. Jeong-Soo Lee, Heung-Soon Kwon, Evacuation Behaviors under the Corridor and Stair Width Variations in Evacuation Experiments, Korea Academy Industrial Cooperation Societyjournal of a paper,Vol.13, No.5, p.2377, p.2379,2012.

7. Gyeongbukmaeil,September

2014

2:01, https://www.kbmaeil.com/news/articleView.html?idxno=331760

8. Won-joo Lee, Chang-Seop Lee, Ki-young Lee, A Study on the Actual Condition of the Obstacles on the Apartment Escape Stairs and the Perception of Residents, Fire Science and Engineering, Vol.31, No.1, p120, 2017.

9. Korea Ministry of Government Legislation, 「Performance-oriented design methods and standards for fire-fighting facilities, etc.」[asterisk1], No.3 (다), Revision December 31, 2019.

10. KOrean Statistical Information Service(KOSIS),Korean Body Size Survey: 120 areas of statistics (male)

11. http://kosis.kr/statHtml/statHtml.do?orgId=115\&tblId=TX_115190170\&conn_path=I2

12. Korean Statistical Information Service,Korean Body Size Survey: 120 areas of statistics (female)

13. http://kosis.kr/statHtml/statHtml.do?orgId=115\&tblId=TX_115190171\&conn_path=I2

14. Satoh, E. at al, "Investigation of converted walking distance considering resistance of topographical features and changes in physical strength by age", Journal of Architecture Planning, pp.133-139, 2006.

15. SFPE, "The SFPE Handbook of Fire Protection Engineering", 5th edition, p.2126, 2013.

16. Stephanie Studenski. at al, "Gait Speed and Survival in Older Adults", American Medical Association, pp.50-51, 2011. 
Analysis of the Impact of Decreasing the Width of Direct Stairs in Apartments on RSET for All Occupants in Korea

17. Korea Ministry of Government Legislation, 「Performance-oriented design methods and standards for fire-fighting facilities, etc. J[Appendix 1] No.3 (내), Revision December 31, 2019.

18. Korea Ministry of Government Legislation, $\ulcorner$ Act on Fire Prevention, Installation, Maintenance, and Safety Control of Fire-Fighting Systems $\rfloor$ Article 10 the second paragraph of paragraph 1, Revision March 24, 2020.

19. Korea National Fire Agency, Detailed standards guidelines for each violation subject to reporting, paragraph 3, September 29, 2010.

20. Korea Seoul Metropolitan Government, $\circ$ ofire marshal, Emergency exit and other safety management notices, Penalties for violations by target, penalty amount, September 29, 2010.

21. Isabirye, A., \& Moloi, K. (2019). Addressing Trainees'concerns In A Professional Development Programme For Innovative Teaching And Learning. The International Journal of Social Sciences and Humanity Studies, 11(1), 1-18. 